Farum

Sociológico

\section{Forum Sociológico}

Série II

$30 \mid 2017$

Internet e ativismos em saúde

\title{
Visibilidades virtuais de uma Associação de Pessoas com Doença Falciforme na Bahia, Brasil : enfrentamentos e empoderamentos pelo Facebook
}

Virtual visibilities of an Association of People with Sickle Cell Disease in Bahia, Brazil : clashes and empowerments by Facebook

Estélio Gomberg, Ana Cristina de Souza Mandarino, Hugo de Carvalho Mandarino Junior e Wilson Couto Borges

\section{OpenEdition}

Journals

Edição electrónica

URL: https://journals.openedition.org/sociologico/1738

DOI: $10.4000 /$ sociologico. 1738

ISSN: $2182-7427$

Editora

CICS.NOVA - Centro Interdisciplinar de Ciências Sociais da Universidade Nova de Lisboa

\section{Refêrencia eletrónica}

Estélio Gomberg, Ana Cristina de Souza Mandarino, Hugo de Carvalho Mandarino Junior e Wilson

Couto Borges, «Visibilidades virtuais de uma Associação de Pessoas com Doença Falciforme na Bahia, Brasil : enfrentamentos e empoderamentos pelo Facebook», Forum Sociológico [Online], 30 | 2017, posto online no dia 30 dezembro 2017, consultado o 31 março 2022. URL: http:// journals.openedition.org/sociologico/1738; DOI: https://doi.org/10.4000/sociologico.1738 


\title{
VISIBILIDADES VIRTUAIS DE UMA ASSOCIAÇÃO DE PESSOAS COM DOENÇA FALCIFORME NA BAHIA, BRASIL: ENFRENTAMENTOS E EMPODERAMENTOS PELO FACEBOOK VIRTUAL VISIBILITIES OF AN ASSOCIATION OF PEOPLE WITH SICKLE CELL DISEASE IN BAHIA, BRAZIL: CLASHES AND EMPOWERMENTS BY FACEBOOK
}

\author{
Estélio Gomberg \\ Universidade Estadual de Santa Cruz (UESC), Departamento de Filosofia e Ciências Humanas, Colegiado de Ciências \\ Sociais \\ Ana Cristina de Souza Mandarino \\ - Universidade Federal da Bahia, Escola de Administração, Programa de Pós-Graduação em Segurança Pública, Justiça e \\ Cidadania \& Instituto Universitário de Lisboa, Centro de Estudos Internacionais (CEI-IUL) \\ Hugo de Carvalho Mandarino Junior \\ - Universidade Estácio de Sá, Faculdade de Medicina, Departamento de Saúde

\section{Wilson Couto Borges} \\ Fundação Oswaldo Cruz, Instituto de Comunicação e Informação Científica e Tecnológica em Saúde (Icict/Fiocruz), \\ Laboratório de Comunicação e Saúde
}

\begin{abstract}
Resumo
O presente estudo teve como objetivo apreender as diversas campanhas virtuais relacionadas à doença falciforme desenvolvidas pela Associação de Pessoas com Doença Falciforme de Ilhéus APEDFI (Bahia/Brasil) - no Facebook, entre os anos de 2012 a 2016. O potencial deste perfil é que permite externar experiências de adoecimentos, de sofrimentos e de solidariedades, rompendo desta maneira uma fronteira: em outros momentos históricos, pareciam ser os meios tradicionais de comunicação o único canal de oferta de temas e conteúdos ao debate público. Com relatos de participantes no perfil da Associação, busca-se eminentemente um empoderamento dos portadores da doença focalizada, estimulando, com palavras e imagens a construção de contextos de interatividades, a disseminação de informações sobre os contextos de tratamentos e as redes de solidariedades à doença.
\end{abstract}

Palavras-chaves: doença falciforme, ciberativismo, Facebook, empoderamento

\begin{abstract}
The objective of this study was to understand the various virtual campaigns related to sickle cell disease, developed by the Association of People with Sickle Disease of Ilhéus - APEDFI (Bahia/ /Brazil) - on Facebook between 2012 and 2016. The potential of this profile is that it allows to express experiences of illness, suffering, and solidarity, thus breaking a boundary: in other historical moments, the traditional means of communication seemed to be the only channel to offer themes and contents to the public debate. With reports from participants in the Association's profile, they seek the empowerment of the patients with the targeted disease, stimulating, with words and images, the construction of interactivity contexts, the dissemination of information about the contexts of treatments and the networks of solidarity to the disease.
\end{abstract}

Keywords: sickle cell disease, cyberactivism, Facebook, empowerment 


\section{Introdução}

O ciberativismo, surgido antes das chamadas mídias sociais ${ }^{1}$, é considerado um lócus virtual onde se expressa uma militância online de diversas áreas, em distintas capilaridades locais e globais, com articulações de instituições e sujeitos sociais, que se utilizam de diversas linguagens, além da organização de uma agenda própria de mobilizações por meio virtual (Antoun, 2002; Arquilla e Ronfeldt, 2001; Deibert, 2000; Gohn, 2003; Rigitano, 2003; Moraes, 2001).

Esta militância social proporciona uma ampliação nos canais de expressões, tendo os meios digitais vindo a ser considerados como um espaço favorável de ampliações e de fluidez das informações com rapidez, ratificando as conexões com interesses comuns em um novo contexto, servindo-se de plataformas de comunicação em toda parte (Castells, 2013a; Safko e Brake, 2010).

Castells (2013a) considera o ciberespaço como um espaço por excelência de sociabilidades, de reivindicações e de solidariedades, emergindo uma nova configuração comunicacional com aberturas de canais de interações de diversos interlocutores propícios a debates, dando novos contornos a formas antes estabelecidas de relação social, sejam no plano físico ou de usos de tecnologias.

Segundo Lévy (1999), o acesso às tecnologias eletrônicas da comunicação oportunizou, especialmente, que jovens vivenciassem novas formas de comunicação, expandindo a vida social e cultural em conexões com contextos e com espaços amplos com dinâmicas comunitárias.

Sendo o ciberespaço um

\footnotetext{
"... novo meio de comunicação que surge da interconexão mundial de computadores. $O$ termo especifica não apenas a infraestrutura material da comunicação digital, mas também o universo oceânico de informações que ela abriga, assim como os seres humanos que navegam e alimentam esse universo" (Lévy, 1999: 17)
}

Este autor aponta que o termo foi criado por Gibson (1991) para designar o universo da comunicação digital, sendo o "dispositivo de comunicação interativo e comunitário que se apresenta como um dos instrumentos privilegiados da inteligência coletiva" (Lévy, 1999: 29).

Este espaço em foco funciona como uma arena multimídia online com linguagens próprias de comunicação, com pluralidade de contextos e de segmentos sociais com subjetividades, que se conectam com interesses múltiplos, sem descolar dos debates e embates sociais reais, com dimensão de complementariedade com o real.
O virtual, conforme Lévy (1996),

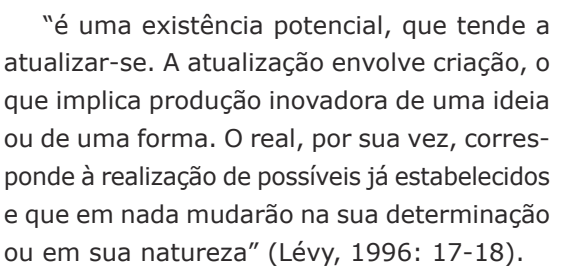

Acrescentando a este debate, Lemos (2003) levanta questões sobre as práticas de ciberativismo como espaço de ações políticas e mediações entre instituições e sujeitos sociais potencializado de conteúdos de diversas linguagens e sentidos, sem entendimento do começo e do fim da onipresença dele.

\footnotetext{
"Alguns ativistas, ou melhor, ciberativistas, estão agindo como porta-voz dos problemas políticos da cibercultura e lutam contra a infantilização do movimento, normalmente levado a cabo pela mídia. Eles agem assim como mediadores, gate keepers, entre o controle por grandes conglomerados mundiais e o cidadão comum. Eles estão mesmo na origem da informática, da internet e da atual cibercultura. Várias formas de ação política são atualmente praticadas tendo como objetivo alertar a população e impedir ações que atingem a liberdade de expressão e a vida privada." (Lemos, 2003: 22)
}

Nessa direção, as produções e as transmissões de informações em blogs e em outras redes de mídias sociais, produzidas por ciberativistas, visam desencadear disseminações de ideias, de críticas e mobilizações sociais, ressignificando o locus das manifestações, o que vem a ser endossado pela direção em que Castells destaca:

\footnotetext{
"As redes de mídia social desempenharam, assim, um importante papel na revolução egípcia. Manifestantes registraram os eventos com seus telefones celulares e compartilharam seus vídeos com pessoas do país e do mundo via YouTube e Facebook, coordenavam-se pelo Twitter e usavam blogs para transmitir amplamente suas opiniões e se envolver em debates." (Castells, 2013b: 54)
}

Em tempos contemporâneos, o ciberativismo traz para cena ações de ativistas que, através de postagens, almejam mobilizações em prol de direitos sociais plurais com transformações tecnológicas na sociedade, através da internet, desencadeando inclusão social e fortalecimento de cidadania através de múltiplas formas de acesso à informação. Pela 
oportunidade de expressões, em espaços virtuais de diversas naturezas, públicos e privados, o ambiente virtual viabiliza a livre expressão, debates, contextualização entre comunicação e democracia (Pompéo e Vieira, 2013).

Todo esse movimento parece estar imerso na perspectiva apontada por Santos (2000) ao observar o conjunto das transformações que os fenômenos da globalização (e da internet, como um de seus correlatos) tende a permitir, especialmente porque é a partir desse momento histórico - o da passagem do século XX ao XXI - que nos é dado a assistir um conjunto de transformações que dá (potencialmente) a todos os atores sociais as mesmas ferramentas, isto é, os mesmos meios de produção. Um dos efeitos mais poderosos que a internet gera é o de todos poderem fazer circular conteúdos para além daqueles que interessam estritamente aos donos do poder.

Por exemplo, a expressão "Primavera Árabe" foi designada pela imprensa internacional para dar conta dos protestos registrados em alguns países do Oriente Médio e da África do Norte, iniciando na Tunísia, em dezembro de 2010, com manifestações populares almejando mudanças políticas e sociais, caracterizada por campanhas, primando por desobediências civis, utilizando-se significativamente de mídias sociais para apontar situações de crises apresentadas em países. ${ }^{2}$

$O$ recurso às mídias sociais nestes contextos colocou em cena a otimização de aparelhos de telefonias móveis para registros e para divulgações tanto visuais quanto verbais dos atos políticos sem a necessidade de possuir site para postagem, tendo eles tecnologia de registros e a velocidade com qualidade de transmissões de dados para ser acessado por milhões de pessoas em diversas partes do planeta, potencializando a evocação do ciberativismo.

Estes protestos também trouxeram para o centro da reflexão as organizações de insatisfações coletivas sem lideranças formais e inúmeros debates acadêmicos e não acadêmicos, com empolgações e ceticismo ao ciberativismo, sobre as significâncias e as influências das mídias sociais nestes confrontos suplantando ordens estabelecidas em Estados até então totalitários e servindo como ferramenta complementar às mobilizações, colaborando nas divulgações juntamente com mídias independentes.

\footnotetext{
"... as insurreições populares no mundo árabe são um ponto de inflexão na história social e política da humanidade. E talvez a mais importante das muitas transformações que a internet induziu e facilitou, em todos os âmbitos da vida, sociedade, economia e cultura. Estamos apenas começando, porque o movimento se acelera, embora a internet seja uma tecnologia antiga, implantada pela primeira vez em 1969" (Rovira, 2011, s/p).
}

No âmbito nacional, as mobilizações via mídias sociais digitais são desencadeadas para fins governamentais e não governamentais. O próprio Estado brasileiro faz uso destas ferramentas para pautar uma série de consultas públicas como forma de fomento (embora por vezes tutelado) de participação política, fornecendo subsídios ao poder público por meio eletrônico de estabelecer agendas de políticas públicas, redundando em algumas ocasiões em ausência de debates.

Por sua vez, na instância não governamental, os usos destas ferramentas são fruto das desigualdades registradas na sociedade brasileira, pautadas em demandas e formulações de agenda dos movimentos sociais, como assinaturas de abaixo-assinados, envios de petições, passeatas, cancelamento de sites e de perfis em mídias sociais entre outros. Tal processo pode provocar o debate no poder legislativo, refletindo o impacto que a influência dos movimentos sociais gera sobre a agenda política. Como um dos exemplos dessa perspectiva, podemos citar a Campanha da Ficha Limpa, com a coleta, conforme Guimarães (2013), de 1,3 milhão de assinaturas e aprovação de Projeto de Lei de iniciativa popular, visando a lisura em candidaturas em eleições no Brasil.

\footnotetext{
"O ano de 2009 foi também o ano em que a campanha reforçou sua presença virtual. Um primeiro grupo de suporte à mobilização no Facebook foi lançado em junho, e a partir daí a iniciativa se estendeu a outros canais de mídias sociais, como Twitter e YouTube. Um primeiro grupo de suporte à campanha foi lançado no Facebook em junho de 2009 - contaria um ano depois com 30 mil seguidores, além de 10 mil assinantes no Twitter" (Guimarães, 2013: 115).
}

A internet possibilitou a organizações ampliação nos espaços de expressões e de atuações na esfera civil, através de elaborações autônomas, ultrapassando o controle histórico e ideológico de meios de comunicação, desencadeando visibilidades públicas com alcance amplo de expressões.

Com tais questões, podemos apontar para o perfil da Associação de Pessoas com Doença Falciforme de Ilhéus, no Estado da Bahia (Brasil), no Facebook, como um objeto de análise que nos permite apreender o quanto, através de suas postagens, há críticas a contextos de tratamentos da doença falciforme, enfermidade que socialmente possui mecanismos de invisibilidades de diversas ordens na sociedade brasileira.

Desta maneira, o presente estudo buscou identificar o ciberativismo desenvolvido pela Associação de Pessoas com Doença Falciforme de Ilhéus (APEDFI) na rede social Facebook, através de postagens 
realizadas por ela e por diversas pessoas agregadas ao seu perfil, desde seu início, no ano de 2012, até maio de 2016, apontando diversos contextos de confrontos frente à doença falciforme, especialmente aqueles relacionados aos descasos sociais do poder público frente a tão grave enfermidade. ${ }^{3}$

A doença falciforme se caracteriza como

\begin{abstract}
"um termo genérico que engloba um grupo de anemias hemolíticas hereditárias caracterizadas pela alteração estrutural na cadeira da betaglobina levando à produção de uma hemoglobina anormal denominada $\mathrm{HbS}$ (derivado do inglês sickle), daí, o nome doença falciforme." (Loureiro e Rozenfeld, 2005: 943).
\end{abstract}

A Associação de Pessoas com Doença Falciforme de Ilhéus (APEDFI) foi fundada em 1997, conta com 160 associados e não possui sede própria nem sítio virtual próprio e seu funcionamento atualmente é realizado em uma unidade pública de saúde de atendimento especializado, na cidade de Ilhéus, na Região Litoral Sul do estado da Bahia.

O potencial social deste perfil reside nas oportunidades de expressões produzidas pela instituição, por portadores da doença e seus familiares, permitindo externar experiêcias de adoecimentos ${ }^{4}$, de sofrimentos, de solidariedades, aumentando desta maneira a circulação de informações sobre o agravo e suas consequências, rompendo com um silenciamento, se tomarmos como parâmetro as narrativas veiculadas pela grande imprensa que, durante muito tempo, ignorou tais iniciativas assim como a importância desta enfermidade.

O espaço deste perfil da Associação nos faz apreender novas modalidades de interações culturais, consolidando as necessidades históricas do homem de buscar formas de pensar, agir e interagir entre si, com a natureza e o sobrenatural, rompendo com a fixidez do local, não se restringindo às barreiras geográficas, possibilitando uma dissociação entre a comunicação e a presença física, motivando uma modalidade de comunicação interativa, igualitária entre os participantes do perfil.

As narrativas contidas nas postagens ilustram, na ótica de Ricouer (1994) os participantes como agentes históricos, pois

"A narrativa constrói a identidade da personagem, que se pode chamar de sua identidade narrativa, construindo a da história narrada. È a identidade da história que constitui a unidade da personagem" (Ricoeur, 1994: 176).

Configura-se uma ressonância desta narrativa no plano da vida concreta e cotidiana, proporcionando um processo de identificação e de interação do indivíduo e da comunidade, visando a busca de sentido e a coerência das ações individuais por meio dela apontando à intersubjetividade e às relações sociais.

Através de novas tecnologias, distintos processos de sociabilidades foram modificados, incidindo sobre linguagens específicas e gerando aproximações de sujeitos sociais de diversos segmentos. A partir de uma observação primária nos movimentos dos participantes do perfil da Associação em questão, pode-se perceber 0 acesso de integrantes de diversas localidades do país, onde estes apontam e registram a participação de indivíduos e diversas associações de doença falciforme ou anemias falciformes sem a necessidade de presença física para a efetivação da comunicação. Em alguns casos, há, inclusive, incidências de fotos com rostos ou com corpos de portadores de doença falciforme, que abordaremos a seguir.

Foram, através de postagens, registradas menções de dificuldades relacionadas ao acesso ao tratamento, dificuldade esta bastante conhecida pelos portadores de doença falciforme no país, conforme dados apontados em perfis de diversas organizações sociais relacionados com doença em redes sociais, assim como menções da complexidade de ausências de políticas públicas voltadas a esta população (Araújo, 2007; Naoum e Naoum, 2004).

Um dos aspectos favoráveis para esta modalidade de comunicação é o fato de que esta permite não só a oportunidade de se expressar diretamente nas redes sociais, mas também concede os mesmos espaços para expressarem diversas posições, possibilitando, a princípio, se manifestarem sem canais de censuras e apontar sentimentos de críticas e de compartilhamentos, como, por exemplo, através de postagens onde estabelecem vínculos solidários com portadores da doença e familiares.

Nestes cenários virtuais, usuários de redes sociais vivenciam relações sem definições concretas e sem interações prévias. Concomitantemente, nesse espaço de ação, parece absolutamente pertinente a metáfora da "liquidez" concebida por Bauman (2001) para compreender modalidades de relações na contemporaneidade, que se estabelecem sem rigidez das noções de espaço e de tempo e com extrema mobilidade presente em setores sociais na contemporaneidade e, por efeito, as relações interpessoais são pautadas no instantâneo com a contemplação da utopia, por este autor, de uma "comunidade".

Nesta sociedade, em que é primaz o instantâneo, a falta de tempo pode ser um dos fatores pelo qual a manifestação de sentimentos envolvidos tenha aparecido com tanta força na internet. Assim, postar um comentário de solidariedade para uma pessoa portadora, além de criar vínculos afetivos como apontamos acima, também traz uma comodidade no período pós-moderno, pois é um meio mais rápido e instantâneo de se expressar, diminuindo distâncias. 
Intencionam-se nestas postagens organizar internamente comunidades com evidência à pessoa, com identidade particular: portador de doença falciforme, dotadas de uma temporalidade em princípio infindável, com intenções de recuperar a memória desta e denunciar em algumas situações as dificuldades de acesso a tratamentos a enfermidade focada, possuidora de uma identidade particular: doente com uma narrativa própria.

Assim, essas comunidades na internet acionam, na "liquidez", mecanismos suplementares através de expressões múltiplas - profanas e religiosas - para modificar os rituais organizados do luto, elaborados pelos grupos sociais. A internet desencadeou processos de transformações em diversos campos na contemporaneidade, incluindo os processos de lutos, e sendo estes registrados também em diversos sítios virtuais e em redes sociais (Cunha Filho, 2009; Gurgel e Kovács, 2011).

\section{Considerações breves}

A doença falciforme, socialmente invisível, é a "argamassa" que sedimenta usuários do perfil da Associação referida na interatividade virtual, proporcionando redes de solidariedades e denunciando as invisibilidades sociais desta enfermidade.

Um dado significativo nestas postagens é a intencionalidade de se conectar em redes virtuais com maior número de pessoas para manifestar sentimentos, que traz um questionamento sobre esta postura na internet, visto que acessar faz parte, em tempos contemporâneos, do cotidiano delas, nas visões de mundo e com possibilidades de acionamentos de diversos papéis sociais, e isto incide na maneira de se portar diante de situações como a enfermidade apresentada.

Nas narrativas de participantes no perfil da Associação busca-se eminentemente um empoderamento dos portadores da doença focalizada, estimulando com postagens que incrementam contextos de interatividades, visando conceber redes de disseminações de informações de educação e saúde e redes de solidariedades. Esse movimento tende a relativizar aquele modelo pelo qual temas, perspectivas, abordagens eram dados a conhecer quase que exclusivamente pela lógica da difusão: era quase que um monopólio da grande mídia. Nestes termos, podemos estar concretamente diante de um cenário onde os atores sociais não apenas aumentem seu poder de falar, mas igualmente o de interagir.

\section{Notas}

1 São exemplos de mídias sociais: Twitter (2006), YouTube (2005), o Facebook (2004) e o extinto Orkut (2004-2014).

2 Sobre "Primavera Árabe" e mídias sociais, consultar: Carvalho Pinto (2011); Tufte (2013).
3 Para entendimento de doença falciforme, consultar: Cançado e Jesus (2007); Guedes (2006); Felix et al. (2010); Zago e Pinto (2007).

4 Sobre experiências de adoecimento, consultar: Duarte e Leal (1998); Gomberg (2008); Kleinman (1980); Young (1981).

\section{Referências bibliográficas}

ANTOUN, H. (2002), A multidão e o futuro da democracia na cibercultura, texto apresentado no GT Comunicação e Sociedade Tecnológica no XI Encontro Anual da COMPós, Rio de Janeiro.

ARAÚJO, P. I. C. (2007), "O autocuidado na doença falciforme", Rev. Bras. Hematol. Hemoter., 29 (3), pp. 239-246.

ARQUILLA, J. e D. Ronfeldt (2001), "Networks, Netwars and the Fight for the Future", First Monday, 6(10), s/p. Disponível em: http://firstmonday. org/issues6_10/ronfe Idt/index.html [acesso em 23 de outubro de 2013].

BAUMAN, Z. (2001), The Individualized Society, Cambridge, Polity Press.

CANÇADO, R. D. e J. A. Jesus (2007), "Sickle Cell Disease in Brazil", Rev. Bras. Hematol. Hemoter., 29 (3), pp. 203-206.

CARVALHO PINTO, V. (2011), "La ola de movimientos pro democracia en Medio Oriente: análisis preliminar de las consecuencias políticas para la región del Golfo Pérsico", in E. Ballesté y M. Férez (orgs.), Medio Oriente y Norte de Africa: reforma, revolución o continuidad?, Ciudad de Mexico, Senado de la Republica Mexicana.

CASTELLS, M. (2013a), Redes de indignação e esperança: movimentos sociais na era da internet, Rio de Janeiro, Zahar.

CASTELLS, M. (2013b), O poder da identidade. A era da informação: economia, sociedade e cultura Volume 2, São Paulo, Paz e Terra.

CUNHA FILHO, P. C. (2009), Cibercepção da morte: luto virtual e misticismo tecnológico, Recife, UFPE.

DEIBERT, R. J. (2000), "International Plug'n Play? Citizen Activism, the Internet and the Global Public Policy", International Studies Perspectives, 1 (3), pp. 255-272.

DUARTE, L. F. D. e O. Leal (orgs.) (1998), Doença, sofrimento e perturbação. Perspectivas etnográficas, Rio de Janeiro, Fiocruz.

FELIX, A. A.; H. M. Souza e S. B. Ribeiro (2010), "Aspectos epidemiológicos e sociais da doença falciforme", Rev. Bras. Hematol. Hemoter., 32 (3), pp. 203-208.

GIBSON, W. (1991), Neuromancer, São Paulo, Aleph.

GOHN, M. da G. (2003), Movimentos sociais no início do século XXI: antigos e novos atores sociais, Petrópolis, Vozes.

GOMBERG, E. (2008), Encontros terapêuticos no terreiro de candomblé Ilê Axé Opô Oxogum Ladê, 
Sergipe/Brasil, tese de doutoramento em Saúde Pública, Salvador, UFBA.

GUEDES, C. (2006), "Itinerários do cuidar em doenças falciformes e suas repercussões na vida de mulheres", Textos \& Contextos, 15 (2), pp. 370-381.

GUIMARÃES, T. (2013), A luta pela visibilidade na campanha Ficha Limpa: mídia, movimentos sociais e combate à corrupção política no Brasil contemporâneo, dissertação de mestrado, Salvador, UFBA

GURGEL, W. B., et al. (2011), "Luto virtual: o processo de elaboração do luto no ciberespaço", Cadernos de Pesquisa, 18 (1), pp. 07-16.

LEMOS, A. (2003), "Cibercultura: alguns pontos para compreender a nossa época", in A. Lemos e P. Cunha (orgs.), Olhares sobre a cibercultura, Porto Alegre, Sulina.

LÉVY, P. (1996), O que é o virtual?, São Paulo, Editora 34.

LÉVY, P. (1999), Cibercultura, São Paulo, Editora 34.

LOUREIRO, M. M. e S. Rozenfeld (2005), "Epidemiologia de internações por doença falciforme no Brasil", Revista de Saúde Pública, 39 (6), pp. 943-949.

KLEINMAN, A. (1980), Patients and Healers in Context of Culture, Berkeley, University of California.

MORAES, D. (2001), o ativismo digital. Disponível em: http://www.uarte.rcts.pt [acesso em 28 de setembro de 2013].

NAOUM, P. C. e F. A. Naoum (2004), Doença das células falciformes, São Paulo, Sarvier.

POMPÉO, W. A. H. e A. D. Vieira (2013), "Do virtual ao real: um estudo de caso acerca do papel do ativismo digital na mobilização e protestos pela tragédia da boate Kiss", Anais do 2.0 Congresso Internacional de Direito e Contemporaneidade: mídias e direitos da sociedade em rede, pp.
555-567. Disponível em: http://www.ufsm.br/ congressodireito/anais [acesso: 28 de setembro de 2013].

RABELO, M. C. M. (2010), "A construção do sentido nos tratamentos religiosos", Revista Eletrônica de Comunicação, Informação \& Inovação em Saúde, 4 (3), pp. 3-11.

RICOUER, P. (1994), O si mesmo como um outro, Campinas, Papirus.

RIGITANO, M. E. C. (2003), "Redes e ciberativismo: notas para uma análise do centro de mídia independente", Anais, I Seminário Interno do Grupo de Pesquisa em Cibercidades, Salvador, FACOM-UFBA.

ROVIRA, J. (2011), "Castells sobre internet e rebelião: 'É só o começo."', OutrasPalavras. Disponível em: http://www.outraspalavras.net/2011/03/01/castells-sobre-internet-e-insurreicao-e-so-o-comeco/ [acesso em 10 de junho de 2016].

SAFKO, L. e D. K. Brake (2010), A Bíblia da mídia social: táticas, ferramentas e estratégias para construir e transformar negócios, São Paulo, Blucher.

SANTOS, M. (2000), Por uma outra globalização: do pensamento único à consciência universal, Rio de Janeiro, Record.

TUFTE, T (2013), "O renascimento da comunicação para a transformação social. Redefinindo a disciplina e a prática depois da 'Primavera Árabe'", Revista Brasileira de Ciências da Comunicação, 36 (2), pp. 61-90.

YOUNG, A (1981), "The Creation of Medical Knowledge: Some Problems in Interpretation", Social Science and Medicine, pp. 379-386.

ZAGO, M. A. e A. C. S. Pinto (2007), "Fisiopatologia das doenças falciformes: da mutação genética à insuficência de múltiplos órgãos", Rev. Bras. Hematol. Hemoter., 29 (3), pp. 207-14.

Recebido a 28/03/2017. Aceite para publicação a 24/10/2017.

Estélio Gomberg (estelio68@gmail.com). Universidade Estadual de Santa Cruz (UESC), Departamento de Filosofia e Ciências Humanas, Colegiado de Ciências Sociais. Campus Soane Nazaré de Andrade, Rodovia Jorge Amado, Km 16, DFCH Bairro Salobrinho, 45662-900 Ilhéus-BA, Brasil.

Ana Cristina de Souza Mandarino (anamandarino@gmail.com). Universidade Federal da Bahia, Escola de Administração, Programa de Pós-Graduação em Segurança Pública, Justiça e Cidadania \& Instituto Universitário de Lisboa, Centro de Estudos Internacionais (CEI-IUL). Universidade Federal da Bahia - UFBA, Escola de Administração PROGESP, Av. Reitor Miguel Calmon s/n - Vale do Canela, 3.0 andar, sala 27, 40110-903 Salvador-BA, Brasil.

Hugo de Carvalho Mandarino Junior (mandarinojr@gmail.com). Universidade Estácio de Sá, Faculdade de Medicina, Departamento de Saúde. Rua Riachuelo, 27 - Centro, 20230-010 Rio de Janeiro-RJ, Brasil.

Wilson Couto Borges (wilson.borges@icict.fiocruz.br). Fundação Oswaldo Cruz, Instituto de Comunicação e Informação Científica e Tecnológica em Saúde (Icict/Fiocruz), Laboratório de Comunicação e Saúde. Av. Brasil, 4365 - Pavilhão Haity Moussatché - Manguinhos, 21040-900 Rio de Janeiro-RJ, Brasil. 